\title{
Cilia in cell signaling and human disorders
}

\author{
Neil A. Duldulao, Jade Li, Zhaoxia Sun ${ }^{\bowtie}$ \\ Department of Genetics, Yale University School of Medicine, 333 Cedar St., SHM I-329A, New Haven, CT 06520, USA \\ \Correspondence: zhaoxia.sun@yale.edu \\ Received June 26, 2010 Accepted July 19, 2010
}

\begin{abstract}
One of the most widespread cellular organelles in nature is cilium, which is found in many unicellular and multicellular organisms. Formerly thought to be a mostly vestigial organelle, the cilium has been discovered in the past several decades to play critical motile and sensory roles involved in normal organogenesis during development. The role of cilia has also been implicated in an ever increasing array of seemingly unrelated human diseases, including blindness, kidney cysts, neural tube defects and obesity. In this article we review some of the recent developments in research on cilia, and how defects in ciliogenesis and function can give rise to developmental disorders and disease.
\end{abstract}

KEYWORDS cilia, ciliogenesis, ciliopathy, model organisms

\section{INTRODUCTION}

The cilium is a hair-like cell surface organelle. Although present on most types of vertebrate cells, with a few exceptions such as nodal cilia in left-right asymmetry of the body plan and cilia on olfactory sensory neurons in odorant perception (Reese, 1965; Nonaka et al., 1998), functions of the cilium in most cells had rarely been studied as late as a decade ago. This picture has been completely changed in the past decade, during which we witnessed an explosion of cilia studies. We now know the basics of the core machinery for cilia biogenesis, the role of cilia in the Hedgehog pathway and the connection between cilia and a wide spectrum of human disease. Yet the regulation of cilia formation in the context of animal development, the roles of cilia in other major signaling pathways and the underlying mechanisms of cilia-related diseases are far from lucid. What is clear is that we can expect cilia research continues to be an active area in the next decade and new findings will provide crucial insights for understanding both basic biology and human diseases.

\section{CILIARY STRUCTURE AND FUNCTION}

The cilium is an appendage-like organelle extending from the surface of a cell. The ciliary membrane is contiguous with the plasma membrane, and covers a microtubule-based structure known as the axoneme (Fig. 1). Anchoring the cilium in place is a modified centrosome, the basal body, at the proximal end of the axoneme (Fig. 1). The ciliary axoneme is composed by a series of nine outer doublets arranged in a concentric circular pattern, and depending on the cell type, these doublets may surround an additional inner doublet in the middle of the circle (" $9+2$ "), or the inner doublet may alternatively be absent (" $9+0$ ") (Fig. 1). In addition, inner and outer dynein arms connected to the outer doublets are responsible for ciliary motility. Historically the $9+2$ doublet configuration has been associated with a motile function for cilia, whereas the $9+0$ configuration has been associated with sensory cilia. However, the motile primary cilium in the

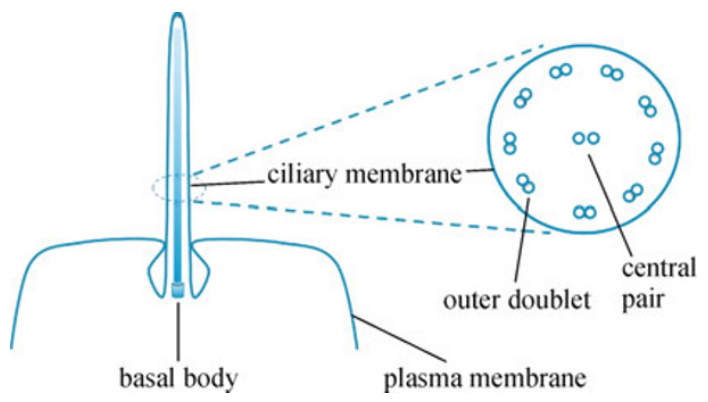

Figure 1. A cartoon depiction of the major components of a " $9+2$ " cilium protruding from the cell surface into the extra-cellular environment. The cilium is anchored in the cell via the basal body. The ciliary membrane is contiguous with the plasma membrane. The axoneme is composed of nine microtubule doublets at the periphery and a central pair of microtubules in the center. For simplicity, dynein arms and radial spokes are not shown. 
mouse node (Nonaka et al., 1998), which is critical for leftright asymmetry, has a $9+0$ configuration, demonstrating that this distinction may be blurred.

At the distal end of the basal body is the transition zone, which is structurally composed of a network of fibers that connects the basal body to the plasma membrane and is thought to form a permeable barrier (Deane et al., 2001). This transition zone has been proposed to serve as a type of pore, through which protein and membrane components can be actively shuttled between cilium and cell body (Deane et al., 2001). In this context, the transition zone may be the location for regulation of the trafficking of ciliary components.

In multicellular organisms, cilia are found on most cells, including the nephron of the kidney, epithelial cells of the trachea, and the external granule layer of the cerebellum, which gives rise to the cerebellar vermis (Sanderson and Sleigh, 1981; Wheatley, 1995; Spassky et al., 2008). A modified cilium comprises the connecting cilium and outer segments of photoreceptor cells in the retina (Wright et al., 2010). Depending on the ciliated tissue type, cilia may serve a variety of biological functions, such as maintaining movement of cerebrospinal fluid in the cerebellum, and sensing noxious substances and sweeping foreign material out of the trachea (Ibañez-Tallon et al., 2004; Shah et al., 2009).

\section{CILIA BIOGENESIS}

Since no protein synthesis machinery exists within the cilium and the axoneme of cilium assembles at the tip (Marshall and Rosenbaum, 2001) instead of the base, protein components must be synthesized within the cell body, and then transported into the cilium by a process known as intraflagellar transport (IFT) (Pedersen and Rosenbaum, 2008). By IFT, protein complexes have been observed to travel in both anterograde (toward the tip of the cilium) and retrograde (back toward the basal body) directions, powered by anterograde kinesin and retrograde dynein motors (Kozminski et al., 1993).

IFT particles are composed of complex A and complex B subunits, which play different roles in the bidirectional movement of cargos along the axoneme of cilia: while complex $A$ is associated more with retrograde transport (Pazour et al., 1998; Piperno et al., 1998), complex B is involved in anterograde transport (Kozminski et al., 1993; Cole et al., 1998). Consistently, mutants of these two complexes show overlapping but distinct phenotypes in cilia morphology: while mutants of complex $B$ genes display severely shortened or total absence of cilia, complex A mutants show stunted cilia with a bulge at the tip filled with complex B components (Perkins et al., 1986; Collet et al., 1998; Piperno et al., 1998; Qin et al., 2001; Schafer et al., 2003; lomini et al., 2009).

In addition to IFT genes, which encode the core machinery for ciliogenesis, an increasing list of genes have been implicated in cilia formation, including genes that regulate cilia length and trafficking of specific components to cilia. In Chlamydomonas, several long flagella mutants have been isolated (McVittie, 1972; Jarvik and Rosenbaum, 1980; Barsel et al., 1988; Asleson and Lefebvre, 1998). Intriguingly, two of them encode kinases, suggesting the involvement of a signaling cascade in regulating cilia length (Berman et al., 2003; Tam et al., 2007). Currently, the underlying mechanism for cilia length control remains elusive. Similarly, the functions of many newly identified genes remain to be fully characterized. Nonetheless, studies on these genes are starting to yield mechanistic insights. An example is BBS genes. After careful analysis, many BBS genes appear to be dispensable for cilia formation at least in some tissues. They are, however, intimately involved in protein trafficking and in mediating ciliary signaling (Lechtreck et al., 2009; Jin et al., 2010).

Another aspect of cilia biogenesis is cell fate determination. In vertebrates, most cells harbor a single cilium. However, in some organs, such as the airway of mammals, the skin of frogs and the pronephric duct of zebrafish, multi-ciliated cells intercalate with single-ciliated cells. Lateral inhibition mediated by the Notch pathway seems to play a critical role in specifying the multi-ciliated versus the single-ciliated fate (Marnellos et al., 2000; Liu et al., 2007; Ma and Jiang, 2007; Tsao et al., 2009).

\section{MODEL ORGANISMS FOR CILIA STUDIES}

Model organisms serve as surrogates to allow experiments that are otherwise not possible in an original system. Multiple systems have been used to analyze the formation and function of cilia. Here, we provide a brief introduction of frequently used organisms. It is worth noting that cultured cell lines have also been used successfully in cilia studies.

\section{Chlamydomonas}

Cilia/Flagella have been extensively studied in the green algae Chlamydomonas; in fact, the major machinery important for the formation and function of cilia, IFT particles, were first discovered in Chlamydomonas (Kozminski et al., 1993). The simple unicellular and biflagellate structure of Chlamydomonas makes it relatively easy to isolate cilia and perform biochemical analysis on ciliary proteins (Cole et al., 1998; Piperno et al., 1998; Rosenbaum and Witman, 2002), a feat that is nearly impossible to achieve in more complex organisms. In addition, the simple structure of Chlamydomonas allows the visualization of IFT without the aid of GFP, the resolution of which is difficult to reach within other organisms (Kozminski et al., 1993). Chlamydomonas is also amendable to genetic analysis, allowing for screens, as well as the generation of a large repertoire of cilia mutants. The release of the nuclear and mitochondrial genome sequence of 
Chlamydomonas provides researchers with better tools for genetic manipulation and informatics. Lessons learned from Chlamydomonas studies on cilia formation and its regulation can then be used to gain insights into the function of cilia in human physiology and diseases.

\section{C. elegans}

C. elegans lacks ciliated epithelial tissues but cilia can be found in the dendritic endings of a large number of sensory neurons. Proteins important for normal cilia formation and functions in mammalian species are well conserved in C. elegans. These genes include IFT genes, such as IFT88, as well as cilia-related disease genes such as PKD1 and PKD2 (Barr and Sternberg, 1999; Barr et al., 2001; Qin et al., 2001). Studies of cilia genes in $C$. elegans can also give insight to the important functional role of cilia in biological processes. For example, homologs of PKD1 and PKD2 in C. elegans, lov-1 and pkd-2, have been shown to be necessary for normal male mating behavior (Barr and Sternberg, 1999; Barr et al., 2001). However, not all mammalian genes important for cilia function are present in the $C$. elegans genome. PKHD1, for example, which encodes Fibrocystin, a protein that is associated with human autosomal recessive polycystic kidney disease, does not have an obvious homolog in C. elegans. In addition to the array of conserved cilia related genes, the large number of tools available in C. elegans, such as the completely sequenced genome, the ease of RNAi knockdown technology, the ability to visualize IFT with the aid of GFP, and the feasibility to conduct genomewide screens, allow effective study of cilia in C. elegans. However, the research of cilia in $C$. elegans is limited by the fact that cilia can only be found in sensory neurons, making it difficult to study tissue-specific roles of cilia.

\section{Drosophila}

Similar to C. elegans, Drosophila does not have ciliated epithelial tissues, and modified cilia are found in the sensory neurons of specialized sensory organs such as bristles. The modified cilia are important for mechano-sensation, audition and olfaction. Some cilia genes are also conserved in Drosophila, such as IFT and BBS genes, which are expressed by the cilia in the sensory neurons (Avidor-Reiss, 2010). The lack of cilia on most Drosophila cells has important functional implications. Specifically, the role of cilia in the Hedgehog (Hh) signal transduction pathway is different between mouse and Drosophila, even though some major principles and players of the pathway are fairly conserved. In Drosophila, in the absence of the Hh ligand, the receptor Patched (Ptc) prevents the protein Smoothened (Smo) from trafficking to the cell surface. Upon binding to the Hh ligand, Ptc is degraded, and Smo is able to traffick to the cell surface and activate downstream effectors (Denef et al., 2000). In contrast, in mouse and other mammals, in the absence of the Hedgehog ligand, Ptc prevents Smo to localize to the cilium, and upon binding of $\mathrm{Hh}$ to Ptc, Smo gains the ability to translocate to the cilium, and activates downstream signals (Huangfu et al., 2003; Corbit et al., 2005; Haycraft et al., 2005; Rohatgi et al., 2007). As a result, mouse IFT mutants exhibit altered hedgehog signaling (Huangfu et al., 2003; Liu et al., 2005; May et al., 2005; Huangfu and Anderson, 2006), while Drosophila IFT mutants do not have Hh phenotypes (Avidor-Reiss, 2010).

\section{Xenopus}

Xenopus laevis is a classic model system for developmental biology studies. The large size and ex utero development of Xenopus embryos make them readily accessible to microdissection and transplantation. In addition, overexpression, morpholino knockdown and transgenesis can be used to manipulate gene functions. Convenient for cilia studies, abundant multi-ciliated cells can be found on the skin of developing Xenopus embryos. Cilia in these cells are oriented, move in concert and drive liquid flow that can be easily visualized. These features have been successfully utilized to study the specification of multi-ciliated cells, the biogenesis of cilia, the relationship among planar cell polarity, flow direction and cilia orientation; all of which are conserved phenomena in mammals (König and Hausen, 1993; Deblandre et al., 1999; Park et al., 2006; Hayes et al., 2007; Mitchell et al., 2007; Park et al., 2008; Vladar and Axelrod, 2008; Mitchell et al., 2009). On the other hand, the tetraploid genome of Xenopus laevis poses a challenge to effective genetic manipulations in this system. Interestingly, Xenopus tropicalis has a diploid genome and shorter generation time. In recent years, it is being actively developed as a genetic model system (reviewed in (Hirsch et al., 2002; Carruthers and Stemple, 2006)).

\section{Zebrafish}

Several unique features of zebrafish make it an excellent model to study the cilium and its role in development and disease. Zebrafish is small in size and each pair of adult fish can produce hundreds of offspring at weekly intervals, making them accessible for large-scale genetic and chemical screens. The optical transparency of zebrafish embryos allows for monitoring of phenotypes in live embryos. This feature is further enhanced by the creation of casper, a fish line that is transparent even as adults (White et al., 2008). In addition, morpholino antisense oligos can be used very effectively and at a relatively high-throughput scale in zebrafish to disrupt gene function (Ekker, 2000; Nasevicius and Ekker, 2000) and recently a zinc-finger endonuclease technique has been used successfully for targeted mutagenesis (Doyon et al., 2008; Meng et al., 2008; Foley et al., 2009). 
The cilium is easily recognizable in zebrafish and is especially enriched in the Kupffer's vesicle, the kidney duct and the neural tube (Kramer-Zucker et al., 2005). Many zebrafish homologs of human disease genes, when mutated, lead to phenotypes that can be directly compared to human symptoms. For example, we demonstrated previously that homologs of $v H N F 1$, a gene associated with human familial GCKD (glomerulocystic kidney disease) (Bingham et al., 2001), and PKD2, a gene associated with autosomal dominant PKD (ADPKD) (Mochizuki et al., 1996), can cause kidney cyst when mutated in zebrafish (Sun et al., 2004). Conversely, arl13b/sco was initially identified as a cystic kidney gene in zebrafish and later associated with Joubert Syndrome in human (Cantagrel et al., 2008). Finally, a collection of cilia mutants, including multiple mutants of IFT genes, was already generated in previous studies (Sun et al., 2004; Tsujikawa and Malicki, 2004; Kramer-Zucker et al., 2005). Taken together, these attributes make zebrafish an excellent system to study the cilium and related kidney diseases.

\section{Mouse}

Cilia studies in mouse led to the appreciation and understanding of the diverse roles cilia play in mammalian development and disease. Cilia are present on almost all mammalian cells, including kidney epithelia, the embryonic node and neurons. With the assistance of the powerful tools in mouse genetics, a large number of cilia mutants are available. These mutants have been used effectively to reveal the role of cilia in Hedgehog signaling (Huangfu et al., 2003; Corbit et al., 2005; Haycraft et al., 2005; Rohatgi et al., 2007) and the establishment of the left-right asymmetry of the body plan (Nonaka et al., 1998, 2002). Furthermore, tissue specific disruption of cilia biogenesis allows researchers to bypass the limitation posed by early lethality of cilia mutants to investigate ciliary functions in different organs and at later developmental stages. For example, using the Cre-lox system to disrupt cilia biogenesis in different tissues, researchers showed that cilia are involved in hair follicle development, bone formation, branching morphogenesis of the mammary gland and in regulating satiety responses (Davenport et al., 2007; Haycraft et al., 2007; Lehman et al., 2009; McDermott et al., 2010).

\section{CILIA PATHWAYS AND SIGNAL TRANSDUCTION}

\section{Hedgehog}

In vertebrate, one signaling pathway that has been shown to have a close relationship with the cilium is the Hedgehog pathway (Huangfu et al., 2003; Liu et al., 2005; May et al., 2005; Huangfu and Anderson, 2006). Hh signaling governs a variety of cellular processes in development, for example, in mammals, the proliferation of the granule cell precursors that eventually give rise to the cerebellar vermis (Dahmane and Ruiz i Altaba, 1999; Wallace, 1999; Wechsler-Reya and Scott, 1999; Spassky et al., 2008). A null mutation of mouse Ift172, wimple, results in significantly altered Patched1 expression in the neural tube (Huangfu et al., 2003). Target genes of $\mathrm{Hh}$ signaling are regulated by the Hh-responsive $\mathrm{Gli}$ family of transcription factors, and overexpressed Gli1, Gli2 and Gli3 have been shown to localize to the distal tip of cilia (Haycraft et al., 2005; Eggenschwiler and Anderson, 2007). In zebrafish, a loss-of-function allele of gli1 and a dominant repressor form of gli2 cause a body axis curvature defect (Karlstrom et al., 2003). Although the dependence of $\mathrm{Hh}$ signaling on the cilium is thought to be conserved in vertebrates including zebrafish and mammals, there are subtle differences between different organisms. For example, gli1 is expressed in zebrafish in the absence of Hh signaling, whereas in mouse $\mathrm{Hh}$ signaling is required for gli1 expression (Bai et al., 2002; Karlstrom et al., 2003). Consistently, a maternal-zygotic ift88 mutant zebrafish that lacks all cilia has a reduced induction of gli1 expression, but expresses low levels of gli1 ectopically (Huang and Schier, 2009). This difference between zebrafish and mammals in the behavior of Hh pathway-responsive genes, such as gli1, may account for the slight difference in phenotypes in zebrafish mutants, compared to the mammalian phenotypes.

Interestingly, available evidence suggests that complex A and $B$ might have different effects on $\mathrm{Hh}$ signaling. In complex $B$ mutants, Hh signaling is mainly inhibited in the neural tube (Huangfu et al., 2003; Haycraft et al., 2005; Liu et al., 2005; May et al., 2005). However, by contrast, in the only two reported mutational studies on IFT complex A components in mice, one on Ift139 and one on Ift122, both mutants show over-activation of the $\mathrm{Hh}$ pathway in the neural tube (Tran et al., 2008; Cortellino et al., 2009). Together, these data suggest that $A$ and $B$ complexes of IFT have distinct functions in overall cilia biogenesis and signaling.

\section{Wnt}

The cilium has also been implicated in Wnt signaling. In zebrafish, disruption of the basal body proteins Bbs1, Bbs4 and $\mathrm{Bbs} 6$ results in defects in convergent extension, which is regulated by noncanonical Wnt/planar cell polarity (PCP) signaling (Gerdes et al., 2007). Suppression of BBS4 in HEK293T cells also results in the stabilization of $\beta$-catenin, a major component of the canonical Wnt pathway (Gerdes et al., 2007). Bbs genes have been shown to interact genetically with the PCP gene Vangl2 in both mice and zebrafish, and Vangl2 localizes to the ciliary axoneme as well as the basal body (Ross et al., 2005). The kif3a mutant, which has ciliogenesis defects, exhibits upregulation of canonical Wnt in mouse embryos, and reveals a role for cilia in restraining the canonical Wnt pathway (Corbit et al., 2008). 
Inversin, which acts as a molecular switch between canonical and noncanonical Wnt pathways, localizes to cilia in MDCK cells (Otto et al., 2003; Simons et al., 2005). In addition, in multiple ciliary mutants, the canonical Wnt pathway was sensitized during early development (Corbit et al., 2005; Gerdes et al., 2007). More directly, in Ift88 and Ift20 mutant mice, non-canonical Wnt phenotypes were observed in the cochlear and kidney ducts respectively (Jonassen et al., 2008; Jones et al., 2008).

Nonetheless other data indicates that the cilium is not overtly required for normal Wnt signaling. Maternal-zygotic ift88 (MZovl) zebrafish mutants, which lack all cilia, undergo normal convergent extension, as indicated by krox20 and myoD expression in the midbrain-hindbrain and somites, respectively (Huang and Schier, 2009). Moreover, these mutants show normal spatial expression of the canonical Wnt target genes axin2, sp5, and sp5l (Huang and Schier, 2009). In mouse, no obvious Wnt-like phenotypes were reported in several IFT mutants (Ocbina et al., 2009). In addition, mutations in canonical Wnt pathway genes wnt3 or lef1 tcf1 double mutants are embryonic lethal very early during development, whereas mice carrying null mutations in IFT genes do not display as severe phenotypes (Eggenschwiler and Anderson, 2007). Currently, the role of cilia in Wnt pathways remains controversial. It is plausible that the role of cilia in Wnt pathways is tissue and stage specific, or that cilia play a minor or redundant role in Wnt pathways.

\section{CILIOPATHIES}

Consistent with its almost ubiquitous distribution and functional importance, the cilium has been linked to an everexpanding list of symptoms in human diseases, ranging from kidney cyst, retinal degeneration and abnormal situs to obesity and diabetes. "Ciliopathy" was coined to describe this diverse spectrum of diseases with a common involvement of the cilium (for a review, see (Hildebrandt et al., 2009)). The connection between polycystic kidney disease (PKD) and the cilium is among one of the best studied. It is thought that cilia on renal epithelial cells detect environmental signals to promote cell differentiation and prevent cell proliferation. Structural or functional defects of cilia can therefore lead to uncontrolled cell proliferation and eventual kidney cyst formation. The central role of the cilium in PKD is supported by the fact that multiple proteins involved in PKD have been found on the cilium and that disruption of cilia formation or function almost inevitably leads to kidney cyst formation (Pazour et al., 2000; Pazour et al., 2002; Yoder et al., 2002a, b; Sun et al., 2004).

Mutations in IFT components generally result in ciliogenesis defects and may cause a wide range of developmental abnormalities, clinical manifestations and ciliopathies such as PKD. For example, an early animal model of PKD was the orpk mouse, which carried a mutation in ift88/polaris (Schrick et al., 1995). ift57 ${ }^{\text {hi3417 }}$, ift81 ${ }^{\text {hi409 }}$, and ift172 ${ }^{\text {hi2211 }}$ mutants in zebrafish develop kidney cysts and body axis curvature (Sun et al., 2004). Defects in the connecting cilium of retinal pigment epithelial cells may result in progressive degeneration of the photoreceptor epithelium, giving rise to clinical presentations, such as retinitis pigmentosa or Leber congenital amaurosis (Murga-Zamalloa et al., 2009; Shintani et al., 2009).

Joubert syndrome (JS) is a rare recessive ciliopathy with an estimated prevalence in the United States of 1 in 100,000 (Parisi et al., 2007). JS is caused by a malformation of the cerebellum, classically resulting in hypotonia and mental retardation, and frequently oculomotor apraxia, ataxia and abnormal breathing patterns (Parisi et al., 2007). In addition to the classical manifestations, some JS patients present with other clinical features, including pre- or post-axial polydactyly, hepatic fibrosis, occipital encephalocele, congenital retinal degeneration and familial juvenile nephronophthisis, a cystic kidney disease that is the most common cause of chronic renal failure in children (Satran et al., 1999; Parisi et al., 2007). As a set, these features are known as Joubert syndrome and related disorders (JSRD). The primary clinical diagnostic criterion of classical JS is the appearance of a "molar tooth sign" on magnetic resonance images of the brain, indicating cerebellar vermis hypoplasia (Maria et al., 1999). While diagnosis of JS with observation of the molar tooth sign is possible by as early as the third trimester of gestation, no specific treatments exist for JS, and patients with nephronophthisis or renal dysplasia typically undergo renal dialysis or transplantation for disease management (Fluss et al., 2006; Parisi et al., 2007).

To date, recessive mutations in nine autosomal genes and one $\mathrm{X}$-linked gene have been found to be associated with Joubert syndrome: NPHP1, NPHP6/CEP290, NPHP8/ RPGRIP1L, CC2D2A, AHI1, MKS3/TMEM67, TMEM216, INPP5E, OFD1 and ARL13B (Table 1) (Dixon-Salazar et al., 2004; Ferland et al., 2004; Parisi et al., 2004; Sayer et al., 2006; Valente et al., 2006; Arts et al., 2007; Baala et al., 2007; Delous et al., 2007; Cantagrel et al., 2008; Gorden et al., 2008; Bielas et al., 2009; Coene et al., 2009; Edvardson et al., 2010). Of these ten, three are also associated with nephronophthisis: NPHP1 (encodes Nephrocystin), NPHP6/ CEP290 (encodes Nephrocystin-6), and NPHP8 (encodes RPGR-interacting protein-1-like protein), revealing considerable clinical and genetic overlap between JSRD and isolated nephronophthisis (Hildebrandt et al., 1997; Sayer et al., 2006; Wolf et al., 2007). However, mutations in the ten JSRDassociated genes are found in less than $50 \%$ of JS patients in some clinical cohorts, indicating that other JSRD-related genes remain undiscovered (Doherty, 2009).

Analyses of the ten genes associated with JSRD implicate a role for cilia in this multisystemic disorder. First of all, nine of the ten known JSRD-associated proteins have been shown to localize to the cilium or the basal body (Table 1). In addition, 
Table 1 Genes associated with Joubert syndrome (JS)

\begin{tabular}{|c|c|c|c|}
\hline disease & protein & gene & notes \\
\hline JBTS1 & $\begin{array}{l}\text { Inositol polyphosphate- } \\
\text { 5-phosphatase E }\end{array}$ & INPP5E & $\begin{array}{l}\text { Observed on ciliary axoneme in cell culture, involved in cilia } \\
\text { stability (Bielas et al., 2009; Jacoby et al., 2009). }\end{array}$ \\
\hline JBTS2 & $\begin{array}{l}\text { Transmembrane } \\
\text { protein } 216\end{array}$ & TMEM216 & $\begin{array}{l}\text { Localized to base of cilia, required for ciliogenesis } \\
\text { (Valente et al., 2010). }\end{array}$ \\
\hline JBTS3 & Jouberin & AHI1 & $\begin{array}{l}\text { Observed on basal bodies, required for primary cilia biogenesis } \\
\text { and vesicular trafficking (Louie et al., 2010). }\end{array}$ \\
\hline JBTS4 & Nephrocystin-1 & NPHP1, SLSN1 & $\begin{array}{l}\text { Observed on transition zones, adherens junctions, focal } \\
\text { adhesions (Donaldson et al., 2000; Donaldson et al., 2002; } \\
\text { Fliegauf et al., 2006). }\end{array}$ \\
\hline JBTS5 & $\begin{array}{l}\text { Nephrocystin-6, } \\
\text { centrosomal } \\
\text { protein of } 290 \mathrm{kD}\end{array}$ & $\begin{array}{l}\text { CEP290, NPHP6, } \\
\text { MKS4, LCA10, BBS14, } \\
\text { SLSN6 }\end{array}$ & $\begin{array}{l}\text { Observed on centrosomes, basal bodies and cilia } \\
\text { (Sayer et al., 2006; Frank et al., 2008; Kim et al., 2008). } \\
\text { Required for cilia formation (Kim et al., 2008). }\end{array}$ \\
\hline JBTS6 & Meckelin & MKS3, TMEM67 & $\begin{array}{l}\text { Observed on ciliary axoneme and plasma membrane (Dawe et } \\
\text { al., 2007). Required for cilia formation } \\
\text { (Dawe et al., 2007; Tammachote et al., 2009). }\end{array}$ \\
\hline JBTS7 & $\begin{array}{l}\text { RPGR-interacting } \\
\text { protein 1-like protein }\end{array}$ & $\begin{array}{l}\text { RPGRIP1L, NPHP8, } \\
\text { MKS5 }\end{array}$ & $\begin{array}{l}\text { Observed on centrosomes, basal bodies } \\
\text { (Vierkotten et al., 2007). }\end{array}$ \\
\hline JBTS8 & $\begin{array}{l}\text { ADP-ribosylation factor- } \\
\text { like protein 13B }\end{array}$ & $A R L 13 B$ & $\begin{array}{l}\text { Observed on ciliary axoneme. Required for cilia formation (Sun } \\
\qquad \begin{array}{c}\text { et al., 2004; Caspary et al., 2007; } \\
\text { Duldulao et al., 2009). }\end{array}\end{array}$ \\
\hline JBTS9 & - & $C C 2 D 2 A$ & $\begin{array}{c}\text { Interacts with Cep290 (Gorden et al., 2008). observed at basal } \\
\text { bodies (Romio et al., 2004; Gorden et al., 2008). Required for } \\
\text { cilia formation (Tallila et al., 2008). }\end{array}$ \\
\hline JBTS10 & - & OFD1 & $\begin{array}{l}\text { Localizes to centrosomes (Romio et al., 2004; Keller et al., } \\
\text { 2005). Required for cilia formation (Ferrante et al., 2006). }\end{array}$ \\
\hline
\end{tabular}

Ten loci have been found to be associated with Joubert syndrome. Some genes associated with JS are also associated with other ciliopathies: BBS, Bardet-Biedl syndrome; LCA, Leber congenital amaurosis; MKS, Meckel syndrome; NPHP, nephronophthisis; SLSN, Senior-Løken syndrome.

mutations in eight JS-associated genes have been found to result in ciliogenesis defects (Table 1). Furthermore, since ciliary defects are closely associated with NPHP, the common involvement of at least three genes in both JSRD and NPHP provides additional support for the role of cilia in JSRD. Collectively, these findings suggest that JS is a ciliopathy whose extracranial manifestations may be traced back to the diverse functional role of cilia in vertebrates.

\section{CONCLUDING REMARKS}

Overlooked for a long time, the antenna-like cilium is now being linked to a growing number of human diseases (Hildebrandt et al., 2009). Protruding from the cell surface into the environment, the ubiquitous cilium is ideally situated to function as a sensor for vertebrate cells. In agreement with its sensory role, multiple receptors, including the Hedgehog receptor Patched, PDGFRa and G protein coupled receptors, have been found on the cilium (Händel et al., 1999; Schneider et al., 2005; Rohatgi et al., 2007; Berbari et al., 2008). Although role of cilia in the $\mathrm{Hh}$ pathway is now well established, the precise function of cilia in other signaling pathways remains to be elucidated. In depth analysis of cilia function in the context of tissue development and homeostasis will be critical for understanding and treating ciliopathies.

\section{REFERENCES}

Arts, H.H., Doherty, D., van Beersum, S.E., Parisi, M.A., Letteboer, S. J., Gorden, N.T., Peters, T.A., Märker, T., Voesenek, K., Kartono, A., et al. (2007). Mutations in the gene encoding the basal body protein RPGRIP1L, a nephrocystin-4 interactor, cause Joubert syndrome. Nat Genet 39, 882-888.

Asleson, C.M., and Lefebvre, P.A. (1998). Genetic analysis of flagellar length control in Chlamydomonas reinhardtii: a new long-flagella locus and extragenic suppressor mutations. Genetics 148, 693-702.

Avidor-Reiss, T. (2010). The cellular and developmental program connecting the centrosome and cilium duplication cycle. Semin Cell Dev Biol 21, 139-141.

Baala, L., Romano, S., Khaddour, R., Saunier, S., Smith, U.M., Audollent, S., Ozilou, C., Faivre, L., Laurent, N., Foliguet, B., et al. (2007). The Meckel-Gruber syndrome gene, MKS3, is mutated in Joubert syndrome. Am J Hum Genet 80, 186-194.

Bai, C.B., Auerbach, W., Lee, J.S., Stephen, D., and Joyner, A.L. (2002). Gli2, but not Gli1, is required for initial Shh signaling and ectopic activation of the Shh pathway. Development 129, 
4753-4761.

Barr, M.M., and Sternberg, P.W. (1999). A polycystic kidney-disease gene homologue required for male mating behaviour in $\mathrm{C}$. elegans. Nature 401, 386-389.

Barr, M.M., DeModena, J., Braun, D., Nguyen, C.Q., Hall, D.H., and Sternberg, P.W. (2001). The Caenorhabditis elegans autosomal dominant polycystic kidney disease gene homologs lov-1 and pkd2 act in the same pathway. Curr Biol 11, 1341-1346.

Barsel, S.E., Wexler, D.E., and Lefebvre, P.A. (1988). Genetic analysis of long-flagella mutants of Chlamydomonas reinhardtii. Genetics 118, 637-648.

Berbari, N.F., Lewis, J.S., Bishop, G.A., Askwith, C.C., and Mykytyn, K. (2008). Bardet-Biedl syndrome proteins are required for the localization of $\mathrm{G}$ protein-coupled receptors to primary cilia. Proc Natl Acad Sci U S A 105, 4242-4246.

Berman, S.A., Wilson, N.F., Haas, N.A., and Lefebvre, P.A. (2003). A novel MAP kinase regulates flagellar length in Chlamydomonas. Curr Biol 13, 1145-1149.

Bielas, S.L., Silhavy, J.L., Brancati, F., Kisseleva, M.V., Al-Gazali, L., Sztriha, L., Bayoumi,R.A., Zaki, M.S., Abdel-Aleem, A., Rosti, R. O., et al. (2009a). Mutations in INPP5E, encoding inositol polyphosphate-5-phosphatase E, link phosphatidyl inositol signaling to the ciliopathies. Nat Genet 41, 1032-1036.

Bingham, C., Bulman, M.P., Ellard, S., Allen, L.I., Lipkin, G.W., Hoff, W.G., Woolf, A.S., Rizzoni, G., Novelli, G., Nicholls, A.J., et al. (2001). Mutations in the hepatocyte nuclear factor-1beta gene are associated with familial hypoplastic glomerulocystic kidney disease. Am J Hum Genet 68, 219-224.

Cantagrel, V., Silhavy, J.L., Bielas, S.L., Swistun, D., Marsh, S.E., Bertrand, J.Y., Audollent, S., Attié-Bitach, T., Holden, K.R., Dobyns, W.B., et al, and the International Joubert Syndrome Related Disorders Study Group. (2008). Mutations in the cilia gene ARL13B lead to the classical form of Joubert syndrome. Am J Hum Genet 83, 170-179.

Carruthers, S., and Stemple, D.L. (2006). Genetic and genomic prospects for Xenopus tropicalis research. Semin Cell Dev Biol 17, 146-153.

Caspary, T., Larkins, C.E., and Anderson, K.V. (2007). The graded response to Sonic Hedgehog depends on cilia architecture. Dev Cell 12, 767-778.

Chang, B., Khanna, H., Hawes, N., Jimeno, D., He, S., Lillo, C., Parapuram, S.K., Cheng, H., Scott, A., Hurd, R.E., et al. (2006). Inframe deletion in a novel centrosomal/ciliary protein CEP290/ NPHP6 perturbs its interaction with RPGR and results in earlyonset retinal degeneration in the rd16 mouse. Hum Mol Genet 15, 1847-1857.

Coene, K.L., Roepman, R., Doherty, D., Afroze, B., Kroes, H.Y., Letteboer, S.J., Ngu, L.H., Budny, B., van Wijk, E., Gorden, N.T., et al. (2009). OFD1 is mutated in X-linked Joubert syndrome and interacts with LCA5-encoded lebercilin. Am J Hum Genet 85, 465-481.

Cole, D.G., Diener, D.R., Himelblau, A.L., Beech, P.L., Fuster, J.C., and Rosenbaum, J.L. (1998). Chlamydomonas kinesin-II-dependent intraflagellar transport (IFT): IFT particles contain proteins required for ciliary assembly in Caenorhabditis elegans sensory neurons. J Cell Biol 141, 993-1008.

Collet, J., Spike, C.A., Lundquist, E.A., Shaw, J.E., and Herman, R.K. (1998). Analysis of osm-6, a gene that affects sensory cilium structure and sensory neuron function in Caenorhabditis elegans. Genetics 148, 187-200.

Corbit, K.C., Aanstad, P., Singla, V., Norman, A.R., Stainier, D.Y., and Reiter, J.F. (2005). Vertebrate Smoothened functions at the primary cilium. Nature 437, 1018-1021.

Corbit, K.C., Shyer, A.E., Dowdle, W.E., Gaulden, J., Singla, V., Chen, M.H., Chuang, P.T., Reiter, J.F. (2008). Kif3a constrains betacatenin-dependent Wnt signalling through dual ciliary and nonciliary mechanisms. Nat Cell Biol 10, 70-76.

Cortellino, S., Wang, C., Wang, B., Bassi, M.R., Caretti, E., Champeval, D., Calmont, A., Jarnik, M., Burch, J., Zaret, K.S., et al. (2009). Defective ciliogenesis, embryonic lethality and severe impairment of the Sonic Hedgehog pathway caused by inactivation of the mouse complex A intraflagellar transport gene Ift122/Wdr10, partially overlapping with the DNA repair gene Med1/Mbd4. Dev Biol 325, 225-237.

Dahmane, N., and Ruiz i Altaba,A. (1999). Sonic hedgehog regulates the growth and patterning of the cerebellum. Development 126, 3089-3100.

Davenport, J.R., Watts, A.J., Roper, V.C., Croyle, M.J., van Groen, T., Wyss, J.M., Nagy, T.R., Kesterson, R.A., and Yoder, B.K. (2007). Disruption of intraflagellar transport in adult mice leads to obesity and slow-onset cystic kidney disease. Curr Biol 17, 1586-1594.

Dawe, H.R., Smith, U.M., Cullinane, A.R., Gerrelli, D., Cox, P., Badano, J.L., Blair-Reid, S., Sriram, N., Katsanis, N., Attie-Bitach, T., et al. (2007). The Meckel-Gruber Syndrome proteins MKS1 and meckelin interact and are required for primary cilium formation. Hum Mol Genet 16, 173-186.

Deane, J.A., Cole, D.G., Seeley, E.S., Diener, D.R., and Rosenbaum, J.L. (2001). Localization of intraflagellar transport protein IFT52 identifies basal body transitional fibers as the docking site for IFT particles. Curr Biol 11, 1586-1590.

Deblandre, G.A., Wettstein, D.A., Koyano-Nakagawa, N., and Kintner, C. (1999). A two-step mechanism generates the spacing pattern of the ciliated cells in the skin of Xenopus embryos. Development 126, 4715-4728.

Delous, M., Baala, L., Salomon, R., Laclef, C., Vierkotten, J., Tory, K., Golzio, C., Lacoste, T., Besse, L., Ozilou, C., et al. (2007). The ciliary gene RPGRIP1L is mutated in cerebello-oculo-renal syndrome (Joubert syndrome type B) and Meckel syndrome. Nat Genet 39, 875-881.

Denef, N., Neubüser, D., Perez, L., and Cohen, S.M. (2000). Hedgehog induces opposite changes in turnover and subcellular localization of patched and smoothened. Cell 102, 521-531.

Dixon-Salazar, T., Silhavy, J.L., Marsh, S.E., Louie, C.M., Scott, L.C., Gururaj, A., Al-Gazali, L., Al-Tawari, A.A., Kayserili, H., Sztriha, L., et al. (2004). Mutations in the AHI1 gene, encoding jouberin, cause Joubert syndrome with cortical polymicrogyria. Am J Hum Genet 75, 979-987.

Doherty, D. (2009). Joubert syndrome: insights into brain development, cilium biology, and complex disease. Semin Pediatr Neurol 16, 143-154.

Donaldson, J.C., Dempsey, P.J., Reddy, S., Bouton, A.H., Coffey, R. J., and Hanks, S.K. (2000). Crk-associated substrate p130(Cas) interacts with nephrocystin and both proteins localize to cell-cell contacts of polarized epithelial cells. Exp Cell Res 256, 168-178.

Donaldson, J.C., Dise, R.S., Ritchie, M.D., and Hanks, S.K. (2002). Nephrocystin-conserved domains involved in targeting to epithelial 
cell-cell junctions, interaction with filamins, and establishing cell polarity. J Biol Chem 277, 29028-29035.

Doyon, Y., McCammon, J.M., Miller, J.C., Faraji, F., Ngo, C., Katibah, G.E., Amora, R., Hocking, T.D., Zhang, L., Rebar, E.J., et al. (2008). Heritable targeted gene disruption in zebrafish using designed zinc-finger nucleases. Nat Biotechnol 26, 702-708.

Duldulao, N.A., Lee, S., and Sun, Z. (2009). Cilia localization is essential for in vivo functions of the Joubert syndrome protein Arl13b/Scorpion. Development 136, 4033-4042.

Edvardson, S., Shaag, A., Zenvirt, S., Erlich, Y., Hannon, G.J., Shanske, A.L., Gomori, J.M., Ekstein, J., and Elpeleg, O. (2010). Joubert syndrome 2 (JBTS2) in Ashkenazi Jews is associated with a TMEM216 mutation. Am J Hum Genet 86, 93-97.

Eggenschwiler, J.T., Anderson, K.V. (2007). Cilia and developmental signaling. Annu Rev Cell Dev Biol 23, 345-373.

Ekker, S.C. (2000). Morphants: a new systematic vertebrate functional genomics approach. Yeast 17, 302-306.

Ferland, R.J., Eyaid, W., Collura, R.V., Tully, L.D., Hill, R.S., Al-Nouri, D., Al-Rumayyan, A., Topcu, M., Gascon, G., Bodell, A., et al. (2004). Abnormal cerebellar development and axonal decussation due to mutations in AHI1 in Joubert syndrome. Nat Genet 36, 1008-1013.

Ferrante, M.I., Zullo, A., Barra, A., Bimonte, S., Messaddeq, N., Studer, M., Dollé, P., and Franco, B. (2006). Oral-facial-digital type I protein is required for primary cilia formation and left-right axis specification. Nat Genet 38, 112-117.

Fliegauf, M., Horvath, J., von Schnakenburg, C., Olbrich, H., Müller, D., Thumfart, J., Schermer, B., Pazour, G.J., Neumann, H.P., Zentgraf, H., et al. (2006). Nephrocystin specifically localizes to the transition zone of renal and respiratory cilia and photoreceptor connecting cilia. J Am Soc Nephrol 17, 2424-2433.

Fluss, J., Blaser, S., Chitayat, D., Akoury, H., Glanc, P., Skidmore, M., and Raybaud, C. (2006). Molar tooth sign in fetal brain magnetic resonance imaging leading to the prenatal diagnosis of Joubert syndrome and related disorders. J Child Neurol 21, 320-324.

Foley, J.E., Yeh, J.R., Maeder, M.L., Reyon, D., Sander, J.D., Peterson, R.T., Joung, J.K., and Raible, D.W. (2009). Rapid mutation of endogenous zebrafish genes using zinc finger nucleases made by Oligomerized Pool ENgineering (OPEN). PLoS ONE 4, e4348.

Frank, V., den Hollander, A.I., Brüchle, N.O., Zonneveld, M.N., Nürnberg, G., Becker, C., Du Bois, G., Kendziorra, H., Roosing, S., Senderek, J., et al. (2008). Mutations of the CEP290 gene encoding a centrosomal protein cause Meckel-Gruber syndrome. Hum Mutat 29, 45-52.

Gerdes, J.M., Liu, Y., Zaghloul, N.A., Leitch, C.C., Lawson, S.S., Kato, M., Beachy, P.A., Beales, P.L., DeMartino, G.N., Fisher, S., et al. (2007). Disruption of the basal body compromises proteasomal function and perturbs intracellular Wnt response. Nat Genet 39, 1350-1360.

Gorden, N.T., Arts, H.H., Parisi, M.A., Coene, K.L., Letteboer, S.J., van Beersum, S.E., Mans, D.A., Hikida, A., Eckert, M., Knutzen, D., et al. (2008). CC2D2A is mutated in Joubert syndrome and interacts with the ciliopathy-associated basal body protein CEP290. Am J Hum Genet 83, 559-571.

Händel, M., Schulz, S., Stanarius, A., Schreff, M., ErdtmannVourliotis, M., Schmidt, H., Wolf, G., and Höllt, V. (1999). Selective targeting of somatostatin receptor 3 to neuronal cilia. Neu- roscience 89, 909-926.

Haycraft, C.J., Banizs, B., Aydin-Son, Y., Zhang, Q., Michaud, E.J., and Yoder, B.K. (2005). Gli2 and Gli3 localize to cilia and require the intraflagellar transport protein polaris for processing and function. PLoS Genet 1, e53.

Haycraft, C.J., Zhang, Q., Song, B., Jackson, W.S., Detloff, P.J., Serra, R., and Yoder, B.K. (2007). Intraflagellar transport is essential for endochondral bone formation. Development 134 , 307-316.

Hayes, J.M., Kim, S.K., Abitua, P.B., Park, T.J., Herrington, E.R., Kitayama, A., Grow, M.W., Ueno, N., and Wallingford, J.B. (2007). Identification of novel ciliogenesis factors using a new in vivo model for mucociliary epithelial development. Dev Biol 312, 115-130.

Hildebrandt, F., Otto, E., Rensing, C., Nothwang, H.G., Vollmer, M., Adolphs, J., Hanusch, H., and Brandis, M. (1997). A novel gene encoding an $\mathrm{SH} 3$ domain protein is mutated in nephronophthisis type 1. Nat Genet 17, 149-153.

Hildebrandt, F., Attanasio, M., and Otto, E. (2009). Nephronophthisis: disease mechanisms of a ciliopathy. J Am Soc Nephrol 20, 23-35.

Hirsch, N., Zimmerman, L.B., and Grainger, R.M. (2002). Xenopus, the next generation: $X$. tropicalis genetics and genomics. Dev Dyn 225, 422-433.

Huang, P., and Schier, A.F. (2009). Dampened Hedgehog signaling but normal Wnt signaling in zebrafish without cilia. Development 136, 3089-3098.

Huangfu, D., and Anderson, K.V. (2006). Signaling from Smo to Ci/ Gli: conservation and divergence of Hedgehog pathways from Drosophila to vertebrates. Development 133, 3-14.

Huangfu, D., Liu, A., Rakeman, A.S., Murcia, N.S., Niswander, L., and Anderson, K.V. (2003). Hedgehog signalling in the mouse requires intraflagellar transport proteins. Nature 426, 83-87.

Ibañez-Tallon, I., Pagenstecher, A., Fliegauf, M., Olbrich, H., Kispert, A., Ketelsen, U.P., North, A., Heintz, N., and Omran, H. (2004). Dysfunction of axonemal dynein heavy chain Mdnah5 inhibits ependymal flow and reveals a novel mechanism for hydrocephalus formation. Hum Mol Genet 13, 2133-2141.

Iomini, C., Li, L., Esparza, J.M., and Dutcher, S.K. (2009). Retrograde intraflagellar transport mutants identify complex $A$ proteins with multiple genetic interactions in Chlamydomonas reinhardtii. Genetics 183, 885-896.

Jacoby, M., Cox, J.J., Gayral, S., Hampshire, D.J., Ayub, M., Blockmans, M., Pernot, E., Kisseleva, M.V., Compère, P., Schiffmann, S.N., et al. (2009). INPP5E mutations cause primary cilium signaling defects, ciliary instability and ciliopathies in human and mouse. Nat Genet 41, 1027-1031.

Jarvik, J.W., and Rosenbaum, J.L. (1980). Oversized flagellar membrane protein in paralyzed mutants of Chlamydomonas reinhardrii. J Cell Biol 85, 258-272.

Jin, H., White, S.R., Shida, T., Schulz, S., Aguiar, M., Gygi, S.P., Bazan, J.F., and Nachury, M.V. (2010). The conserved BardetBiedl syndrome proteins assemble a coat that traffics membrane proteins to cilia. Cell 141, 1208-1219.

Jonassen, J.A., San Agustin, J., Follit, J.A., and Pazour, G.J. (2008). Deletion of IFT20 in the mouse kidney causes misorientation of the mitotic spindle and cystic kidney disease. J Cell Biol 183, 377-384.

Jones, C., Roper, V.C., Foucher, I., Qian, D., Banizs, B., Petit, C., Yoder, B.K., and Chen, P. (2008). Ciliary proteins link basal body 
polarization to planar cell polarity regulation. Nat Genet 40, 69-77. Karlstrom, R.O., Tyurina, O.V., Kawakami, A., Nishioka, N., Talbot, W. S., Sasaki, H., and Schier, A.F. (2003). Genetic analysis of zebrafish gli1 and gli2 reveals divergent requirements for gli genes in vertebrate development. Development 130, 1549-1564.

Keller, L.C., Romijn, E.P., Zamora, I., Yates, J.R. 3rd, and Marshall, W. F. (2005). Proteomic analysis of isolated chlamydomonas centrioles reveals orthologs of ciliary-disease genes. Curr Biol 15, 1090-1098.

Kim, J., Krishnaswami, S.R., and Gleeson, J.G. (2008). CEP290 interacts with the centriolar satellite component PCM-1 and is required for Rab8 localization to the primary cilium. Hum Mol Genet 17, 3796-3805.

König, G., and Hausen, P. (1993). Planar polarity in the ciliated epidermis of Xenopus embryos. Dev Biol 160, 355-368.

Kozminski, K.G., Johnson, K.A., Forscher, P., and Rosenbaum, J.L. (1993). A motility in the eukaryotic flagellum unrelated to flagellar beating. Proc Natl Acad Sci U S A 90, 5519-5523.

Kramer-Zucker, A.G., Olale, F., Haycraft, C.J., Yoder, B.K., Schier, A. F., and Drummond, I.A. (2005). Cilia-driven fluid flow in the zebrafish pronephros, brain and Kupffer's vesicle is required for normal organogenesis. Development 132, 1907-1921.

Lechtreck, K.F., Johnson, E.C., Sakai, T., Cochran, D., Ballif, B.A., Rush, J., Pazour, G.J., Ikebe, M., and Witman, G.B. (2009). The Chlamydomonas reinhardtii BBSome is an IFT cargo required for export of specific signaling proteins from flagella. J Cell Biol 187, $1117-1132$.

Lehman, J.M., Laag, E., Michaud, E.J., and Yoder, B.K. (2009). An essential role for dermal primary cilia in hair follicle morphogenesis. J Invest Dermatol 129, 438-448.

Liu, A., Wang, B., and Niswander, L.A. (2005). Mouse intraflagellar transport proteins regulate both the activator and repressor functions of Gli transcription factors. Development 132, 3103-3111.

Liu, Y., Pathak, N., Kramer-Zucker, A., and Drummond, I.A. (2007). Notch signaling controls the differentiation of transporting epithelia and multiciliated cells in the zebrafish pronephros. Development 134, 1111-1122.

Louie, C.M., Caridi, G., Lopes, V.S., Brancati, F., Kispert, A., Lancaster, M.A., Schlossman, A.M., Otto, E.A., Leitges, M., Gröne, H.J., et al. (2010). AHI1 is required for photoreceptor outer segment development and is a modifier for retinal degeneration in nephronophthisis. Nat Genet 42, 175-180.

Ma, M., and Jiang, Y.J. (2007). Jagged2a-notch signaling mediates cell fate choice in the zebrafish pronephric duct. PLoS Genet 3, e18.

Maria, B.L., Quisling, R.G., Rosainz, L.C., Yachnis, A.T., Gitten, J., Dede, D., and Fennell, E. (1999). Molar tooth sign in Joubert syndrome: clinical, radiologic, and pathologic significance. J Child Neurol 14, 368-376.

Marnellos, G., Deblandre, G.A., Mjolsness, E., and Kintner, C. (2000). Delta-Notch lateral inhibitory patterning in the emergence of ciliated cells in Xenopus: experimental observations and a gene network model. Pac Symp Biocomput 5, 326-337.

Marshall, W.F., and Rosenbaum, J.L. (2001). Intraflagellar transport balances continuous turnover of outer doublet microtubules: implications for flagellar length control. J Cell Biol 155, 405-414.

May, S.R., Ashique, A.M., Karlen, M., Wang, B., Shen, Y., Zarbalis, K.,
Reiter, J., Ericson, J., and Peterson, A.S. (2005). Loss of the retrograde motor for IFT disrupts localization of Smo to cilia and prevents the expression of both activator and repressor functions of Gli. Dev Biol 287, 378-389.

McDermott, K.M., Liu, B.Y., Tlsty, T.D., and Pazour, G.J. (2010). Primary cilia regulate branching morphogenesis during mammary gland development. Curr Biol 20, 731-737.

McVittie, A. (1972). Flagellum mutants of Chlamydomonas reinhardii. J Gen Microbiol 71, 525-540.

Meng, X., Noyes, M.B., Zhu, L.J., Lawson, N.D., and Wolfe, S.A. (2008). Targeted gene inactivation in zebrafish using engineered zinc-finger nucleases. Nat Biotechnol 26, 695-701.

Mitchell, B., Jacobs, R., Li, J., Chien, S., and Kintner, C. (2007). A positive feedback mechanism governs the polarity and motion of motile cilia. Nature 447, 97-101.

Mitchell, B., Stubbs, J.L., Huisman, F., Taborek, P., Yu, C., and Kintner, C. (2009). The PCP pathway instructs the planar orientation of ciliated cells in the Xenopus larval skin. Curr Biol 19, 924-929.

Mochizuki, T., Wu, G., Hayashi, T., Xenophontos, S.L., Veldhuisen, B., Saris, J.J., Reynolds, D.M., Cai, Y., Gabow, P.A., Pierides, A., et al. (1996). PKD2, a gene for polycystic kidney disease that encodes an integral membrane protein. Science 272, 1339-1342.

Murga-Zamalloa, C.A., Swaroop, A., and Khanna, H. (2009). RPGRcontaining protein complexes in syndromic and non-syndromic retinal degeneration due to ciliary dysfunction. J Genet 88, $399-407$.

Nasevicius, A., and Ekker, S.C. (2000). Effective targeted gene 'knockdown' in zebrafish. Nat Genet 26, 216-220.

Nonaka, S., Tanaka, Y., Okada, Y., Takeda, S., Harada, A., Kanai, Y., Kido, M., and Hirokawa, N. (1998). Randomization of left-right asymmetry due to loss of nodal cilia generating leftward flow of extraembryonic fluid in mice lacking KIF3B motor protein. Cell 95, 829-837.

Nonaka, S., Shiratori, H., Saijoh, Y., and Hamada, H. (2002). Determination of left-right patterning of the mouse embryo by artificial nodal flow. Nature 418, 96-99.

Ocbina, P.J., Tuson, M., Anderson, K.V., and Heisenberg, C.-P. (2009). Primary cilia are not required for normal canonical Wnt signaling in the mouse embryo. PLoS ONE 4, e6839.

Otto, E.A., Schermer, B., Obara, T., O'Toole, J.F., Hiller, K.S., Mueller, A.M., Ruf, R.G., Hoefele, J., Beekmann, F., Landau, D., et al. (2003). Mutations in INVS encoding inversin cause nephronophthisis type 2, linking renal cystic disease to the function of primary cilia and left-right axis determination. Nat Genet 34, 413-420.

Parisi, M.A., Bennett, C.L., Eckert, M.L., Dobyns, W.B., Gleeson, J. G., Shaw, D.W., McDonald, R., Eddy, A., Chance, P.F., and Glass, I.A. (2004). The NPHP1 gene deletion associated with juvenile nephronophthisis is present in a subset of individuals with Joubert syndrome. Am J Hum Genet 75, 82-91.

Parisi, M.A., Doherty, D., Chance, P.F., and Glass, I.A. (2007). Joubert syndrome (and related disorders) (OMIM 213300). Eur J Hum Genet 15, 511-521.

Park, T.J., Haigo, S.L., and Wallingford, J.B. (2006). Ciliogenesis defects in embryos lacking inturned or fuzzy function are associated with failure of planar cell polarity and Hedgehog signaling. Nat Genet 38, 303-311.

Park, T.J., Mitchell, B.J., Abitua, P.B., Kintner, C., and Wallingford, J. 
B. (2008). Dishevelled controls apical docking and planar polarization of basal bodies in ciliated epithelial cells. Nat Genet 40, 871-879.

Pazour, G.J., Wilkerson, C.G., and Witman, G.B. (1998). A dynein light chain is essential for the retrograde particle movement of intraflagellar transport (IFT). J Cell Biol 141, 979-992.

Pazour, G.J., Dickert, B.L., Vucica, Y., Seeley, E.S., Rosenbaum, J.L., Witman, G.B., and Cole, D.G. (2000). Chlamydomonas IFT88 and its mouse homologue, polycystic kidney disease gene $\operatorname{tg} 737$, are required for assembly of cilia and flagella. J Cell Biol 151, 709-718.

Pazour, G.J., San Agustin, J.T., Follit, J.A., Rosenbaum, J.L., and Witman, G.B. (2002). Polycystin-2 localizes to kidney cilia and the ciliary level is elevated in orpk mice with polycystic kidney disease. Curr Biol 12, R378-R380.

Pedersen, L.B., and Rosenbaum, J.L. (2008). Intraflagellar transport (IFT) role in ciliary assembly, resorption and signalling. Curr Top Dev Biol 85, 23-61.

Perkins, L.A., Hedgecock, E.M., Thomson, J.N., and Culotti, J.G. (1986). Mutant sensory cilia in the nematode Caenorhabditis elegans. Dev Biol 117, 456-487.

Piperno, G., Siuda, E., Henderson, S., Segil, M., Vaananen, H., and Sassaroli, M. (1998). Distinct mutants of retrograde intraflagellar transport (IFT) share similar morphological and molecular defects. J Cell Biol 143, 1591-1601.

Ross, A.J., May-Simera, H., Eichers, E.R., Kai, M., Hill, J., Jagger, D. J., Leitch, C.C., Chapple, J.P., Munro, P.M., Fisher, S., et al. (2005). Disruption of Bardet-Biedl syndrome ciliary proteins perturbs planar cell polarity in vertebrates. Nat Genet 37, 1135-1140.

Qin, H., Rosenbaum, J.L., and Barr, M.M. (2001). An autosomal recessive polycystic kidney disease gene homolog is involved in intraflagellar transport in $\mathrm{C}$. elegans ciliated sensory neurons. Curr Biol 11, 457-461.

Reese, T.S. (1965). Olfactory cilia in the frog. J Cell Biol 25, 209 230.

Rohatgi, R., Milenkovic, L., and Scott, M.P. (2007). Patched1 regulates hedgehog signaling at the primary cilium. Science 317, 372-376.

Romio, L., Fry, A.M., Winyard, P.J., Malcolm, S., Woolf, A.S., and Feather, S.A. (2004). OFD1 is a centrosomal/basal body protein expressed during mesenchymal-epithelial transition in human nephrogenesis. J Am Soc Nephrol 15, 2556-2568.

Rosenbaum, J.L., and Witman, G.B. (2002). Intraflagellar transport. Nat Rev Mol Cell Biol 3, 813-825.

Sanderson, M.J., and Sleigh, M.A. (1981). Ciliary activity of cultured rabbit tracheal epithelium: beat pattern and metachrony. J Cell Sci 47, 331-347.

Satran, D., Pierpont, M.E., and Dobyns, W.B. (1999). Cerebellooculo-renal syndromes including Arima, Senior-Löken and $\mathrm{COACH}$ syndromes: more than just variants of Joubert syndrome. Am J Med Genet 86, 459-469.

Sayer, J.A., Otto, E.A., O'Toole, J.F., Nurnberg, G., Kennedy, M.A., Becker, C., Hennies, H.C., Helou, J., Attanasio, M., Fausett, B.V., et al. (2006). The centrosomal protein nephrocystin- 6 is mutated in Joubert syndrome and activates transcription factor ATF4. Nat Genet 38, 674-681.

Schafer, J.C., Haycraft, C.J., Thomas, J.H., Yoder, B.K., and Swoboda, P. (2003). XBX-1 encodes a dynein light intermediate chain required for retrograde intraflagellar transport and cilia assembly in Caenorhabditis elegans. Mol Biol Cell 14, 2057-2070.
Schneider, L., Clement, C.A., Teilmann, S.C., Pazour, G.J., Hoffmann, E.K., Satir, P., and Christensen, S.T. (2005). PDGFRalphaalpha signaling is regulated through the primary cilium in fibroblasts. Curr Biol 15, 1861-1866.

Schrick, J.J., Onuchic, L.F., Reeders, S.T., Korenberg, J., Chen, X.N., Moyer, J.H., Wilkinson, J.E., and Woychik, R.P. (1995). Characterization of the human homologue of the mouse $\operatorname{Tg} 737$ candidate polycystic kidney disease gene. Hum Mol Genet 4, 559-567.

Shah, A.S., Ben-Shahar, Y., Moninger, T.O., Kline, J.N., and Welsh, M.J. (2009). Motile cilia of human airway epithelia are chemosensory. Science $325,1131-1134$.

Shintani, K., Shechtman, D.L., and Gurwood, A.S. (2009). Review and update: current treatment trends for patients with retinitis pigmentosa. Optometry 80, 384-401.

Simons, M., Gloy, J., Ganner, A., Bullerkotte, A., Bashkurov, M., Krönig, C., Schermer, B., Benzing, T., Cabello, O.A., Jenny, A., et al. (2005). Inversin, the gene product mutated in nephronophthisis type II, functions as a molecular switch between Wnt signaling pathways. Nat Genet, 37, 537-543.

Spassky, N., Han, Y.G., Aguilar, A., Strehl, L., Besse, L., Laclef, C., Ros, M.R., Garcia-Verdugo, J.M., and Alvarez-Buylla, A. (2008). Primary cilia are required for cerebellar development and Shhdependent expansion of progenitor pool. Dev Biol 317, 246-259.

Sun, Z., Amsterdam, A., Pazour, G.J., Cole, D.G., Miller, M.S., and Hopkins, N. (2004). A genetic screen in zebrafish identifies cilia genes as a principal cause of cystic kidney. Development 131, 4085-4093.

Tallila, J., Jakkula, E., Peltonen, L., Salonen, R., and Kestilä, M. (2008). Identification of CC2D2A as a Meckel syndrome gene adds an important piece to the ciliopathy puzzle. Am J Hum Genet 82, 1361-1367.

Tam, L.W., Wilson, N.F., and Lefebvre, P.A. (2007). A CDK-related kinase regulates the length and assembly of flagella in Chlamydomonas. J Cell Biol 176, 819-829.

Tammachote, R., Hommerding, C.J., Sinders, R.M., Miller, C.A., Czarnecki, P.G., Leightner, A.C., Salisbury, J.L., Ward, C.J., Torres, V.E., Gattone, V.H. 2nd, et al. (2009). Ciliary and centrosomal defects associated with mutation and depletion of the Meckel syndrome genes MKS1 and MKS3. Hum Mol Genet 18, 3311-3323.

Tran, P.V., Haycraft, C.J., Besschetnova, T.Y., Turbe-Doan, A., Stottmann, R.W., Herron, B.J., Chesebro, A.L., Qiu, H., Scherz, P.J., Shah, J.V., et al. (2008). THM1 negatively modulates mouse sonic hedgehog signal transduction and affects retrograde intraflagellar transport in cilia. Nat Genet 40, 403-410.

Tsao, P.N., Vasconcelos, M., Izvolsky, K.I., Qian, J., Lu, J., and Cardoso, W.V. (2009). Notch signaling controls the balance of ciliated and secretory cell fates in developing airways. Development 136, 2297-2307.

Tsujikawa, M., and Malicki, J. (2004). Intraflagellar transport genes are essential for differentiation and survival of vertebrate sensory neurons. Neuron 42, 703-716.

Valente, E.M., Silhavy, J.L., Brancati, F., Barrano, G., Krishnaswami, S.R., Castori, M., Lancaster, M.A., Boltshauser, E., Boccone, L., AlGazali, L., et al, and the International Joubert Syndrome Related Disorders Study Group. (2006). Mutations in CEP290, which encodes a centrosomal protein, cause pleiotropic forms of Joubert 
syndrome. Nat Genet 38, 623-625.

Valente, E.M., Logan, C.V., Mougou-Zerelli, S., Lee, J.H., Silhavy, J. L., Brancati, F., lannicelli, M., Travaglini, L., Romani, S., Illi, B., et al. (2010). Mutations in TMEM216 perturb ciliogenesis and cause Joubert, Meckel and related syndromes. Nat Genet 42, 619 625.

Vierkotten, J., Dildrop, R., Peters, T., Wang, B., and Rüther, U. (2007). $\mathrm{Ftm}$ is a novel basal body protein of cilia involved in Shh signalling. Development 134, 2569-2577.

Vladar, E.K., and Axelrod, J.D. (2008). Dishevelled links basal body docking and orientation in ciliated epithelial cells. Trends Cell Biol 18, 517-520.

Wallace, V.A. (1999). Purkinje-cell-derived Sonic hedgehog regulates granule neuron precursor cell proliferation in the developing mouse cerebellum. Curr Biol 9, 445-448.

Wechsler-Reya, R.J., and Scott, M.P. (1999). Control of neuronal precursor proliferation in the cerebellum by Sonic Hedgehog. Neuron 22, 103-114.

Wheatley, D.N. (1995). Primary cilia in normal and pathological tissues. Pathobiology 63, 222-238.
White, R.M., Sessa, A., Burke, C., Bowman, T., LeBlanc, J., Ceol, C., Bourque, C., Dovey, M., Goessling, W., Burns, C.E., et al. (2008). Transparent adult zebrafish as a tool for in vivo transplantation analysis. Cell Stem Cell 2, 183-189.

Wolf, M.T., Saunier, S., O'Toole, J.F., Wanner, N., Groshong, T., Attanasio, M., Salomon, R., Stallmach, T., Sayer, J.A., Waldherr, R., et al. (2007). Mutational analysis of the RPGRIP1L gene in patients with Joubert syndrome and nephronophthisis. Kidney Int 72, 1520-1526.

Wright, A.F., Chakarova, C.F., Abd El-Aziz, M.M., and Bhattacharya, S.S. (2010). Photoreceptor degeneration: genetic and mechanistic dissection of a complex trait. Nat Rev Genet 11, 273-284.

Yoder, B.K., Hou, X., and Guay-Woodford, L.M. (2002a). The polycystic kidney disease proteins, polycystin-1, polycystin-2, polaris, and cystin, are co-localized in renal cilia. J Am Soc Nephrol 13, 2508-2516.

Yoder, B.K., Tousson, A., Millican, L., Wu, J.H., Bugg, C.E. Jr, Schafer, J.A., and Balkovetz, D.F. (2002b). Polaris, a protein disrupted in orpk mutant mice, is required for assembly of renal cilium. Am J Physiol Renal Physiol 282, F541-F552. 